\title{
A gestão dos recursos naturais nas organizações certificadas pela norma NBR ISO 14001
}

\author{
Celso Machado Juniora*, Leonel Mazzalib, Maria Tereza Saraiva de Souzac, \\ Cristiane Jaciara Furlaneto ${ }^{\mathrm{d}}$, Leandro Campi Prearo ${ }^{\mathrm{e}}$ \\ a*celsomachado1@gmail.com, USCS, Brasil \\ bleonel_mazzali@uol.com.br, FACCAMP,Brasil \\ 'mtereza@uninove.br, UNINOVE, Brasil \\ ${ }^{\mathrm{d}}$ crisjaciara@ig.com.br, UNIP, Brasil \\ eleandro.prearo@uscs.edu.br, USCS, Brasil
}

\begin{abstract}
Resumo
0 estudo destaca um conjunto de variáveis associadas aos processos de controle e às ações para mitigar o consumo dos recursos nas operações com o objetivo de verificar se as empresas certificadas pela norma NBR ISO 14001 apresentam procedimentos de gestão ambiental significativamente diferentes dos adotados pelas empresas não certificadas por essa norma. É uma pesquisa descritiva assentada em uma amostra composta por 649 empresas de diferentes ramos de atividade, que disponibilizaram informações para a publicação na revista Análise Gestão Ambiental (2008). Foram objeto de estudo os seguintes recursos: água, energia elétrica, combustíveis, lenha/carvão e recursos minerais. A utilização de tratamento estatístico, consubstanciada na regressão logística e no quiquadrado, permitiu evidenciar que as empresas certificadas pela norma NBR ISO 14001 acentuam um conjunto maior dos fatores ambientais em sua gestão por meio de controles, ações e programas estruturados, demonstrando assim maior preocupação socioambiental.
\end{abstract}

Palavras-chave

Gestão ambiental. Sistema de gestão ambiental. ISO 14001.

\section{Introdução}

A preocupação ambiental se configura como tema presente na sociedade, nos poderes públicos e nas organizações, mais claramente manifestado na necessidade de preservação do meio ambiente e na perpetuação de fontes de recursos. Esse movimento torna-se perceptível no final do século XX, mais precisamente a partir da década de 1970. Segundo Seiffert (2005) e Barbieri (2007), somente nas três últimas décadas do século XX os aspectos ambientais passaram a ser debatidos em profundidade. A Conferência Mundial sobre o Meio Ambiente, realizada em 1972, na cidade de Estocolmo, constitui um importante marco dessa nova fase.

A identificação de um conjunto amplo de problemas ambientais exige abordagens sistêmicas e integradoras, incorporando várias disciplinas concernentes às relações de trabalho, aos processos de produção, ao consumo, à saúde e ao meio ambiente (FRANCO, 2002).

Hoffman (2005) aponta vantagens competitivas para as empresas decorrentes da adoção de procedimentos que incorporam a abordagem socioambiental, destacando-se:

1) Reuso, reciclagem ou reutilização dos insumos voltados à prevenção da poluição e das emissões de gases geradores de efeito estufa - GGEE; e

2) Aumento de eficiência de produtos e processos, favorecendo a redução do consumo de recursos naturais, de energia e de combustíveis.

Para Barbieri (2007), o atual estágio da gestão ambiental se constitui em um processo evolutivo composto por um conjunto de fases, o qual é passível de implantação gradual mediante práticas apropriadas. Assim sendo, a empresa pode se posicionar quanto 
ao êxito obtido até determinado momento, bem como a quanto ainda falta para atender a um estágio considerado adequado pelo poder público e pela sociedade. As demandas envolvendo o meio ambiente ainda estão em fase de construção, de tal forma que a empresa, entendida como madura em seu processo de gestão ambiental, pode apresentar deficiências, caracterizando-se assim o estabelecimento de uma nova fase a ser atendida.

Nesse contexto, a certificação pela norma NBR ISO 14001 (Sistemas de Gestão Ambiental - requisitos com orientação para o uso) vem se configurando como uma alternativa, pois contempla um conjunto de requisitos norteadores da incorporação da variável ambiental na gestão das organizações. De um lado, a emissão de certificado de atendimento à norma por organismos independentes possibilita a visualização pela sociedade da preocupação ambiental. De outro, auditorias periódicas de manutenção da certificação, que verificam a aderência da organização à norma e aos requisitos legais.

Se a certificação da organização possibilita a adoção de um modelo de gestão apoiado na transparência das ações e na garantia de atendimento legal, evidencia-se a necessidade de análise da conduta das empresas certificadas vis-à-vis às não certificadas. Dessa forma, o presente artigo pretende verificar se as empresas certificadas pela norma NBR ISO 14001 apresentam procedimentos de gestão ambiental diferentes dos utilizados pelas empresas não certificadas por essa norma.

Trata-se de pesquisa descritiva assentada em uma amostra composta por 649 empresas de diferentes ramos de atividade, que disponibilizaram informações para a publicação na revista Análise Gestão Ambiental (2008). 0 estudo destaca um conjunto de variáveis que descrevem os procedimentos de controle e as ações para mitigar o consumo dos recursos nas operações, classificando as empresas que compõem a amostra em dois grupos: as que possuem certificação pela norma NBR 1 SO 14001 - Sistemas de Gestão Ambiental e as empresas não certificadas. A hipótese é de que as empresas certificadas apresentam programas estruturados de gestão ambiental diferentes das empresas não certificadas.

\section{As organizações e a abordagem ambiental contemporânea: a NBR ISO 14001 como núcleo de um modelo de gestão sustentável}

As empresas possuem uma importante parcela de responsabilidade no objetivo de alcançar o desenvolvimento sustentável. Segundo Slack et al. (2002), a magnitude do impacto ambiental possui uma relação direta com a parcela consumidora da população, os processos produtivos e os produtos que consomem. Dessa forma, as empresas se deparam com novas exigências de seus clientes, que passam a valorizar os fatores ecológicos no momento da compra de um produto ou serviço.

Para Rohrich e Cunha (2004), a gestão ambiental está relacionada ao conjunto de políticas e práticas operacionais e administrativas que incorporam o contexto amplo da empresa e da sociedade. Tal conjunto inclui a saúde e a segurança das pessoas, bem como a proteção do meio ambiente, por meio da eliminação ou mitigação de impactos e danos ambientais advindos do planejamento, implantação, operação, ampliação, realocação ou desativação de empreendimentos ou atividades. Incluem-se aí todas as fases do ciclo de vida do produto. Os autores ressaltam a importância do meio ambiente não somente sobre as bases econômicas, mas também sobre a saúde pública.

A gestão das organizações se caracteriza por uma variedade de posturas, que resultam em diferentes graus de desenvolvimento e comprometimento com as questões ambientais. Nesse contexto, Barbieri (2007) propõe uma divisão em estágios, em que o primeiro estágio é denominado de controle da poluição, restrito ao cumprimento da legislação ambiental e atendimento às pressões da comunidade. No segundo estágio, denominado integração preventiva, o foco se concentra na utilização eficiente dos insumos, com a abordagem ambiental se expandindo da área manufatureira para o conjunto da empresa. No terceiro estágio, a abordagem ambiental é incorporada à estratégia da organização.

Em decorrência da natureza contemporânea das variáveis ambientais, as organizações se deparam com o desafio de introduzir protocolos e condutas em seu modelo de gestão. Diante da necessidade de ajustar e/ou alterar suas atividades, um caminho natural são modelos de gestão estabelecidos especificamente para essa situação. Dentre as alternativas, destaca-se o modelo expresso na norma NBR ISO 14001, abrangendo uma abordagem sistêmica voltada ao equacionamento dos impactos ambientais gerados pelas atividades da organização. Ao lado de condutas e ferramentas para a gestão ambiental, a norma impulsiona a adequação das instalações e a redução dos impactos das operações.

A série de normas NBR ISO 14000, que contém a norma NBR ISO 14001, foi criada com o objetivo de estabelecer estruturas e procedimentos para a melhoria contínua do desempenho ambiental das empresas. A adoção da norma demanda uma mudança cultural na organização, requerendo capacitação dos funcionários, implantação de programas/sistemas de comunicação, 
definição de padrões internos, reformulação dos processos produtivos e dos equipamentos de proteção ambiental.

Segundo Fryxell e Szeto (2002), os possíveis benefícios da certificação pela norma NBR ISO 14001 são adequação às conformidades regulatórias, redução de custos advindos de melhor utilização dos recursos, atendimento às expectativas dos clientes e da sociedade e melhora na reputação corporativa. Zeng et al. (2005) ampliam esse escopo, incluindo os seguintes benefícios: qualificação para entrada no mercado internacional, universalização dos procedimentos de gestão ambiental com os protocolos das operações internas, redução de desperdícios para o gerenciamento corporativo e aumento da consciência ambiental dos fornecedores.

A revisão dos principais trabalhos de autores americanos, canadenses, europeus, japoneses e chineses, voltados ao estudo dos sistemas certificados de gestão ambiental, em particular a NBR ISO 14001 e o Esquema de Auditoria Ecoambiental (Emas), evidencia três grandes focos de análise:

1) Identificação dos fatores que afetam a incorporação dos sistemas certificados de gestão ambiental;

2) Relação entre a implementação dos sistemas certificados e inovações organizacionais (práticas de gestão ambiental) de produto e de processo, associados à utilização/ao consumo de materiais e de energia; e

3) Relação entre a utilização dos sistemas certificados e os efeitos (resultados) sobre a denominada "performance ambiental" das empresas.

Na primeira vertente, Boiral $(2003$, 2007) demonstra que, embora sejam comuns as pressões para a introdução dos denominados sistemas certificados, como as $1 \mathrm{SO} 9000$ e 14001, a absorção das práticas pela organização ocorre segundo formas distintas e em diferentes graus. Impelidas por pressões externas, as empresas interpretam os sistemas certificados com base em valores, normas, recursos e competências, resultando em considerável heterogeneidade no processo de implementação.

Yin e Schmeidler (2009) identificam dois vetores no processo de implementação da NBR ISO 14001: grau de integração com as operações e inclusão de elementos de controle da performance ambiental.

Convém lembrar que a NBR ISO 14001 abrange um conjunto de práticas/normas flexível, desenhado para aplicação em qualquer tipo de organização, independentemente do porte, do ramo de atividade ou da localização. Estabelece-se assim uma ampla margem de manobra para a administração, com diferentes graus de integração com as operações (BOIRAL, 2003, 2007). Algumas empresas podem fazer ajustes mínimos, visando unicamente obter a certificação, de modo que o sistema certificado não vai além daquilo que está "colocado no papel".

No seu estudo sobre o processo de implementação da NBR ISO 14001 em um conjunto selecionado de empresas canadenses, Boiral (2007) identificou quatro estratégias (ou graus) de integração da 150 com o sistema operacional: ritual, dissociado, mobilizado e integração pró-ativa. Quando a integração é ritual e/ou dissociada, as práticas não são discutidas e não ocorre o envolvimento da organização. Em contrapartida, na integração mobilizadora e/ou pró-ativa ocorre, a partir do engajamento dos agentes, a mudança de práticas e normas.

Delmas (2003) comentou que, da mesma forma que a ISO 9000, a NBR ISO 14001 não enfatiza os resultados, tais como redução da poluição ou do consumo de energia, mas os processos. Nessa direção, fica a critério da administração a introdução de padrões de mensuração da performance, ou, mais precisamente, da especificação de critérios de medida e de sua evolução, considerando o estágio do sistema de gestão ambiental. Em razão disso, Yin (2003) sugere a inclusão de critérios para avaliação da perfomance ambiental na NBR ISO 14001.

González, Sarkis e Adenso-Diaz (2008), tomando como universo de análise a cadeia automotiva localizada na Espanha, realizaram estudo com objetivo semelhante ao do presente trabalho. A proposta dos autores foi analisar a presença de diferenças nas práticas de gestão ambiental entre empresas que possuem alguma forma de sistema certificado de gestão ambiental (NBR ISO 14001 e Emas) e as que não possuem qualquer tipo de sistema.

A estratégia de pesquisa utilizada foi uma survey (levantamento de dados por meio de questionário estruturado). Um total de 157 respondentes forneceu informações sobre a existência ou não da certificação e das práticas de gestão ambiental na organização.

Os autores constataram a presença de práticas de gestão ambiental distintas nos dois grupos de empresas. Ademais, concluem

[...] que existe uma associação entre a implementação dos sistemas de gestão ambiental certificados e outras práticas de gestão ambiental. Esses resultados para a indústria automotiva espanhola suportam pesquisas prévias que mostram que tal relação existe. Uma importante implicação é que a certificação abre a oportunidade para a emergência de um ambiente favorável à adoção de outras práticas de preservação ambiental [...] (GONZÁLEZ; SARKIS; ADENSO-DIAZ, 2008, p. 1033)

Como se percebe, além das práticas de gestão ambiental inerentes à NBR ISO 14001, o processo de implementação pode gerar um ambiente propício 
à emergência de novas práticas e, em especial, de novas tecnologias.

Essa é a preocupação de Khanna, Deltas e Harrington (2009). Os autores investigaram a influência do sistema de gestão da qualidade ambiental (TQEM) sobre o grau de incorporação pelas empresas de tecnologias que previnem a poluição. 0 referencial empírico da pesquisa são 167 empresas integrantes do índice S\&P 500 (500 maiores empresas com ações negociadas na Bolsa de Nova York). Essas empresas forneceram informações para o Toxics Release Inventory (TRI) e responderam à survey sobre a adoção de práticas de gestão ambiental, conduzida pelo Investor Research Responsibility Center, no período 1994-1996.

Os autores encontraram evidências de que o sistema de gestão da qualidade ambiental (TQEM) cria um ambiente organizacional que encoraja a identificação de oportunidades para a redução da poluição.

No que se refere à terceira vertente, vários autores analisaram as implicações dos sistemas certificados sobre a performance ambiental das empresas; no entanto, com resultados contrastantes.

Os trabalhos de Anton, Deltas e Khanna (2004), Potoski e Prakash (2005) e Arimura, Hibikid e Katayama (2008) encontraram evidências de que a adoção do sistema certificado de gestão ambiental está relacionada à minimização dos impactos ambientais das operações.

Por seu turno, Jiang e Bansal (2003) concluem que a implementação da NBR ISO 14001 não propicia valor funcional adicional no âmbito interno à organização; somente agrega valor no âmbito externo, associado ao reconhecimento e à credibilidade do procedimento.

Yin e Schmeidler (2009) argumentam que esses trabalhos chegam a resultados contraditórios por negligenciar a heterogeneidade do processo de implementação da NBR ISO 14001, conforme apontado por Boiral (2007). Os autores se propõem a verificar a relação existente entre a referida heterogeneidade e a perfomance ambiental. A pesquisa se apoia em uma survey, efetivada entre julho de 2005 e agosto de 2006, junto a empresas americanas certificadas.

Os autores concluíram que "[...] as empresas que integram ativamente às suas operações os padrões propostos pela NBR ISO 14001 têm maior probabilidade de obter os benefícios ambientais derivados [...]" (YIN; SCHMEIDLER, 2009, p. 473). Ademais

[...] as empresas que incorporam critérios de mensuração da performance ambiental no processo de implantação da ISO 14001 têm maior probabilidade de obter incrementos na sua performance ambiental do que as empresas que o fazem em menor grau [...] (YIN; SCHMEIDLER, 2009, p. 482).
Finalmente, cabe menção a Oliveira e Serra (2010), um dos poucos trabalhos nacionais recentes. Com base em pesquisa tipo survey realizada junto a empresas industriais certificadas com a norma NBR ISO 14001 no Estado de São Paulo, os autores evidenciam os seguintes benefícios associados à perfomance ambiental:

1) Motivação dos colaboradores para atingir metas e objetivos ambientais;

2) Incentivo ao desenvolvimento de ações ambientais preventivas, evitando custos imprevistos; e

3) Contribuição para a redução de consumo de energia elétrica, água, gás, óleo e combustível no processo produtivo.

Com relação à contribuição da NBR ISO 14001 para a inovação tecnológica, a pesquisa obteve somente uma concordância parcial das empresas.

Em síntese, o sistema de gestão ambiental certificado pode se constituir em um fator que modifica a estrutura e a cultura da organização, configurando-se como elemento de diferenciação na abordagem da gestão ambiental. Esse é o ponto a ser demonstrado pela pesquisa efetivada.

\section{Método de pesquisa}

A pesquisa analisa a conduta das organizações na abordagem ambiental e nos procedimentos empregados na gestão de suas atividades por meio da prática de controle e ações para mitigar o consumo dos recursos decorrentes de suas operações.

Trata-se de uma pesquisa descritiva assentada em dados secundários. Segundo Cervo, Bervian e Silva (2007), as pesquisas descritivas têm o objetivo de propiciar maior entendimento sobre a frequência com que um fenômeno ocorre, sua correlação e conexão com outros fenômenos.

A amostra é composta por 649 empresas que disponibilizaram suas informações para a publicação na revista Análise Gestão Ambiental (2008). A revista em questão realizou, durante o ano de 2008, um trabalho de 4 meses, envolvendo 20 profissionais no processo de distribuir e captar questionários, com posterior análise de consistência dos dados e preparo para publicação. A revista fez as totalizações das respostas, porém não estabeleceu estudos ou análises, objetivando identificar correlações entre os dados obtidos. Vale destacar que os questionários foram encaminhados e respondidos diretamente pelas empresas por meio de seus representantes legais.

A seleção da referida publicação para a obtenção dos dados para análise se assenta em dois fatores. 0 primeiro está relacionado à sistemática empregada na coleta dos dados, que utilizou questionário com 
Tabela 1. Empresas certificadas NBR ISO 14001.

\begin{tabular}{|c|c|c|}
\hline Caracteristica da empresa & Quantidade & Porcentagem $(\%)$ \\
\hline Não certificada NBR ISO 14001 & 339 & 52,2 \\
\hline Certificada NBR ISO 14001 & 310 & 47,8 \\
\hline Total & 649 & 100 \\
\hline
\end{tabular}

Fonte: Elaborada pelos autores.

perguntas fechadas e diretas a serem respondidas pelos representantes das empresas, com posterior análise de consistência das informações fornecidas. 0 segundo fator diz respeito às variáveis pesquisadas, que se alinham ao objetivo estabelecido neste estudo, gestão dos recursos utilizados.

A amostra foi dividida em dois grupos de atenção: as empresas que possuem certificação pela norma NBR ISO 14001 - Sistemas de Gestão Ambiental (ASSOCIAÇÃO..., 2004) e as empresas não certificadas. A Tabela 1 apresenta a composição da amostra.

Com o objetivo de diferenciar os procedimentos adotados pelos dois grupos de empresas, foram utilizadas as seguintes variáveis:

1) Água: monitora com indicadores, reusa, adota meta de redução, tem programa estruturado e tem ações de conscientização dos funcionários;

2) Energia elétrica: monitora com indicadores, adota meta de redução, tem programa estruturado e tem ações de conscientização dos funcionários;

3) Óleo combustível: monitora com indicadores, adota meta de redução, tem programa estruturado;

4) Lenha/carvão: monitora com indicadores, adota meta de redução, tem programa estruturado (nesse caso a lenha e o carvão são empregados como fonte de geração de energia); e

5) Recursos minerais: monitora com indicadores, adota meta de redução, tem programa estruturado.

\section{Tratamento estatístico dos dados}

Com base no conjunto de variáveis expressas na seção anterior, o estudo trata de verificar a hipótese de que são marcantes (nível de significância de 0,05 ) as diferenças entre os dois grupos de empresas - as certificadas pela norma NBR ISO 14001 e as não certificadas. Utilizou-se para tratamento estatístico dos dados o software SPSS (Statistical Package for Social Sciences).

Para verificar a existência de diferenças significativas entre os dois grupos de empresas, foi utilizada a análise de regressão logística. Para fins de aplicação da técnica estatística, a variável dependente - existência da certificação pela norma NBR ISO 14001 - foi representada por 1, enquanto a ausência desta foi representada por 0.0 fator característico na interpretação dos coeficientes da regressão logística é a necessidade de saber apenas a ocorrência do evento ou não, para então usar um valor dicotômico como variável dependente, e, a partir desse valor, o procedimento prevê estimativa da probabilidade de que o evento ocorrerá ou não (HAIR JUNIOR et al., 2005).

Segundo Prearo (2008), a aplicação da técnica estatística multivariada de regressão logística objetiva investigar a dependência entre as variáveis ou ainda predizer uma variável-resposta a partir de um grupo de variáveis explicativas. Ainda segundo o autor, as técnicas estatísticas de análise multivariada, como a regressão logística, apresentam superposições matemáticas e estatísticas que, se não atendidas, podem influenciar de forma negativa o resultado. Neste estudo, a variável-resposta é a certificação ou não da empresa diante da norma NBR ISO 14001, enquanto as variáveis explicativas são os procedimentos adotados para gestão da utilização da água, da energia elétrica, do óleo combustível, da lenha e carvão e dos recursos minerais, abrangendo:

1) Monitoramento do consumo por meio de indicadores;

2) Processo de reuso;

3) Estabelecimento de metas de redução no consumo;

4) Programa estruturado para gestão; e

5) Ações de conscientização dos funcionários para o consumo racional.

0 conjunto de variáveis explicativas também se apresenta no formato binário.

0 atendimento à premissa de ausência de multicolinearidade foi verificado a partir do exame das correlações de Spearman entre as variáveis independentes integrantes do modelo, as quais não apresentaram valores superiores a 0,70 em nenhuma das relações, sugerindo a não existência de problemas no modelo estatístico adotado.

Quanto à premissa de adequação do tamanho da amostra, a relação casos-variáveis independentes é de 43 (649 casos para 15 variáveis independentes), valor superior a 20 proposto por Hair Junior et al. (2005).

0 método de seleção empregado na análise objeto deste estudo utiliza como estatística de referência a função de verossimilhança, a qual pode ser definida como a probabilidade de se obter resultados da amostra, das estimativas dos parâmetros do modelo logístico.

Para identificar as variáveis independentes com maior poder explicativo, foi utilizado o teste do quiquadrado com significância de 5\%, conforme a Tabela 2.

Pode-se rejeitar a hipótese nula nas seguintes variáveis independentes: a água é monitorada por indicadores, a água possui processo de reuso, a empresa adota metas de redução no consumo de água, a empresa possui programa estruturado para a gestão 
da água e a empresa tem ações de conscientização dos funcionários para o consumo racional da água. Nesse sentido, o fato de a empresa ser certificada na norma NBR ISO 14001 está associado à dependência no processo de gestão da água.
Da mesma forma, pode-se rejeitar a hipótese nula nas seguintes variáveis independentes: a energia elétrica é monitorada por indicadores, a empresa adota metas de redução no consumo de energia elétrica, a empresa possui programa estruturado para a gestão

Tabela 2. Como as empresas realizam a gestão da energia e dos recursos naturais.

\begin{tabular}{|c|c|c|c|c|c|c|c|}
\hline \multirow{2}{*}{ Item em análise } & \multirow{2}{*}{$\begin{array}{c}\text { Condição da } \\
\text { empresa diante } \\
\text { da norma NBR } \\
\text { ISO } 14001\end{array}$} & \multicolumn{3}{|c|}{$\begin{array}{l}\text { A gestão da empresa atua } \\
\text { nesta variável de controle }\end{array}$} & \multirow{2}{*}{$\begin{array}{c}\text { Qui- } \\
\text { quadrado } \\
\text { de Pearson }\end{array}$} & \multirow{2}{*}{$\begin{array}{l}\text { Significância } \\
\text { assintótica } \\
\text { bilateral }\end{array}$} & \multirow{2}{*}{ Obs. } \\
\hline & & Não & Sim & Total & & & \\
\hline \multirow{2}{*}{ A água é monitorada por indicadores. } & Não certificada & 145 & 194 & 339 & \multirow{2}{*}{98,660} & \multirow{2}{*}{, 000} & \multirow{2}{*}{-} \\
\hline & Certificada & 26 & 284 & 310 & & & \\
\hline \multirow{2}{*}{ A água possui processo de reuso. } & Não certificada & 210 & 129 & 339 & \multirow{2}{*}{25,173} & \multirow{2}{*}{, 000} & \multirow{2}{*}{ - } \\
\hline & Certificada & 131 & 179 & 310 & & & \\
\hline \multirow{2}{*}{$\begin{array}{l}\text { A empresa adota metas de redução no consumo } \\
\text { da água. }\end{array}$} & Não certificada & 162 & 177 & 339 & \multirow{2}{*}{30,427} & \multirow{2}{*}{, 000} & \multirow{2}{*}{-} \\
\hline & Certificada & 83 & 227 & 310 & & & \\
\hline \multirow{2}{*}{$\begin{array}{l}\text { A empresa possui programa estruturado para } \\
\text { gestão da água. }\end{array}$} & Não certificada & 278 & 61 & 339 & \multirow{2}{*}{65,632} & \multirow{2}{*}{,000 } & \multirow{2}{*}{-} \\
\hline & Certificada & 162 & 148 & 310 & & & \\
\hline \multirow{2}{*}{$\begin{array}{l}\text { A empresa tem ações de consciência dos } \\
\text { funcionários para o consumo racional da água. }\end{array}$} & Não certificada & 120 & 219 & 339 & \multirow{2}{*}{6,988} & $0 \cap 8$ & - \\
\hline & Certificada & 80 & 230 & 310 & & ,UUठ & - \\
\hline A eneraia elétrice é monitorade nor indicadorec & Não certificada & 121 & 218 & 339 & & & \\
\hline & Certificada & 33 & 277 & 310 & 56,134 & ,000 & - \\
\hline A emp. adota metas de redução no consumo de & Não certificada & 170 & 169 & 339 & 31031 & 000 & - \\
\hline energia elétrica. & Certificada & 89 & 221 & 310 & & & \\
\hline A emp. possui prog. estruturado para gestão da & Não certificada & 256 & 83 & 339 & 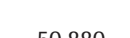 & 000 & \\
\hline energia elétrica. & Certificada & 150 & 160 & 310 & Ju,000 & , & \\
\hline A emp. tem ações de consciência dos func. para & Não certificada & 126 & 213 & 339 & 32386 & 066 & _ \\
\hline o consumo racional da energia elétrica. & Certificada & 94 & 216 & 310 & 3,300 & , & - \\
\hline 0 óleo combustível é monitorado por & Não certificada & 186 & 153 & 339 & 31647 & 000 & - \\
\hline indicadores. & Certificada & 102 & 208 & 310 & & & \\
\hline A empresa adota metas de redução no consumo & Não certificada & 211 & 128 & 339 & 568 & 210 & * \\
\hline de óleo combustível. & Certificada & 178 & 132 & 310 & 1,000 & & \\
\hline A emp. possui prog. estruturado para gestão do & Não certificada & 291 & 48 & 339 & 29205 & 000 & - \\
\hline óleo combustível. & Certificada & 211 & 99 & 310 & 29,203 & , & \\
\hline 0 consumo de lenha e carvão é monitorado por & Não certificada & 292 & 47 & 339 & 726 & 2010 & * \\
\hline indicadores. & Certificada & 274 & 36 & 310 &, 136 & ,391 & \\
\hline A emp. adota metas de redução no consumo de & Não certificada & 307 & 32 & 339 & 597 & 417 & * \\
\hline lenha e carvão. & Certificada & 286 & 24 & 310 & & & \\
\hline A emp. possui prog. estruturado para gestão de & Não certificada & 322 & 17 & 339 & 2077 & 084 & - \\
\hline lenha e carvão. & Certificada & 284 & 26 & 310 & & & \\
\hline A empresa não utiliza esses recursos, logo não & Não certificada & 78 & 261 & 339 & 3513 & 061 & ** \\
\hline se aplica. & Certificada & 53 & 257 & 310 & נוכ, & , & \\
\hline 0 consumo de recursos minerais é monitorado & Não certificada & 293 & 46 & 339 & 25 & 00 & \\
\hline por indicadores. & Certificada & 218 & 92 & 310 & 25,095 & , & - \\
\hline A emp. adota metas de redução no consumo de & Não certificada & 298 & 41 & 339 & 5.487 & 019 & - \\
\hline recursos minerais. & Certificada & 252 & 58 & 310 & & & \\
\hline A emp. possui prog. estruturado para gestão de & Não certificada & 319 & 20 & 339 & 2094 & 005 & \\
\hline recursos minerais. & Certificada & 272 & 38 & 310 & 8,044 & , & - \\
\hline A empresa não utiliza recursos minerais, logo & Não certificada & 128 & 211 & 339 & 180 & 2777 ( & ** \\
\hline não se aplica. & Certificada & 130 & 180 & 310 & 1,180 & |l & \\
\hline
\end{tabular}

*Valores não considerados na análise de regressão logística, pois apresentam significância superior a 10\%. **Valores não considerados na análise de regressão logística, pois não são pertinentes a essa abordagem. Fonte: Elaborada pelos autores. 
da energia elétrica. Pode-se afirmar, portanto, que há dependência entre o processo de gestão da energia elétrica e o fato de a empresa ser certificada na norma NBR ISO 14001. Os valores obtidos demonstram que o conjunto de empresas certificadas pratica o controle e a redução do consumo de energia elétrica em seu processo de gestão.

0 monitoramento da energia elétrica por indicadores em 89,4\% das empresas certificadas merece destaque. $\mathrm{Na}$ abordagem de conscientização dos funcionários para o consumo racional da energia elétrica, não se observa essa dependência; logo não há diferença entre os dois grupos de empresas nesse item de análise.

Pode-se rejeitar também a hipótese nula nas variáveis independentes: o óleo combustível é monitorado por indicadores, a empresa possui programa estruturado para a gestão do óleo combustível. Pode-se afirmar que há dependência entre o processo de gestão do óleo combustível e o fato de a empresa ser certificada na norma NBR ISO 14001. Os valores obtidos demonstram que o conjunto de empresas certificadas pratica o monitoramento e possui programa estruturado em seu processo de gestão. Na abordagem de metas de redução no consumo de óleo combustível, não se observa essa dependência; logo não há diferença entre os dois grupos de empresas nesse item de análise.

Com relação ao consumo de lenha e carvão, pode-se rejeitar a hipótese nula nas seguintes variáveis: é monitorada por indicadores, a empresa adota metas de redução no consumo de lenha e carvão, a empresa possui programa estruturado para a gestão de lenha e carvão. Pode-se afirmar que não há dependência entre o processo de gestão de lenha/carvão e o fato de a empresa ser certificada na norma NBR ISO 14001. Destaca-se que, nos quesitos referentes ao monitoramento por indicadores e à existência de metas de consumo, se observa percentualmente valores maiores nas empresas não certificadas. A análise demonstra que esse item é válido para apenas 131 empresas das 649 pesquisadas, parcela de $20 \%$, indicando que o carvão/a lenha é uma fonte de energia com menor aplicação em comparação à energia elétrica.

Pode-se rejeitar a hipótese nula nas seguintes variáveis: o consumo de recursos minerais é monitorado por indicadores, a empresa adota metas de redução no consumo e a empresa possui programa estruturado para a gestão desses recursos. Pode-se afirmar que há dependência entre processo de gestão dos recursos minerais e o fato de a empresa ser certificada na norma NBR ISO 14001. Os valores obtidos demonstram que o conjunto de empresas certificadas pratica o controle e a redução do consumo dos recursos minerais em seu processo de gestão. A análise demonstra que esse item é valido para 258 empresas das 649 pesquisadas, o que reduz a amostragem, porém sem invalidar o estudo. Essa redução indica que os recursos minerais são necessários apenas para 40\% das empresas pesquisadas.

\section{Análise dos resultados}

A primeira análise consiste em verificar os resultados da combinação binária entre a variável principal em relação a um conjunto de variáveis explicativas. 0 objetivo é revelar se as empresas certificadas pela norma NBR ISO 14001 estabelecem um modelo de gestão ambiental distinto das empresas não certificadas. Vale destacar que a norma NBR ISO 14001 - Sistemas de Gestão Ambiental (ASSOCIAÇÃO..., 2004) possui em seu escopo de requisitos a demanda por controle, gestão e redução dos aspectos e recursos ambientais.

Para verificação da qualidade do modelo, foi executado o teste de log-verossimilhança. A razão entre os logaritmos da verossimilhança do modelo ajustado e do modelo saturado é chamada razão de verossimilhança e seque uma distribuição qui-quadrado. Segundo Hair et al. (2005), tal teste é equivalente ao teste $\mathrm{F}$ da regressão linear múltipla. A Tabela 3 apresenta o valor da estatística qui-quadrado obtida, indicando um bom ajuste do modelo.

Ainda com o intuito de verificar a qualidade do ajuste do modelo, foi aplicada a estatística de Hosmer e Lemeshow, que mede a correspondência entre os valores reais e os previstos da variável dependente, utilizada para testar as classificações esperadas e observadas. A hipótese nula para esse teste é de que as classificações previstas são iguais às observadas. Nesse sentido, a expectativa é de aceitar (não rejeitar) a hipótese nula.

A estatística qui-quadrado para o teste de Hosmer e Lemeshow é de 5,824, com nível de significância de 0,666 , conforme demonstra a Tabela 3, pertencendo dessa forma à área de não rejeição da hipótese nula.

Quanto à capacidade de explicação da variável dependente pelas variáveis independentes selecionadas, os valores das estatísticas de $\mathrm{R}^{2}$ são relativamente baixos, sugerindo que há outras variáveis

Tabela 3. Estatísticas e indicadores de ajuste do modelo logístico.

\begin{tabular}{lrrrl} 
& $\mathrm{R}^{2}$ & \multicolumn{1}{c}{$\chi^{2}$} & gl & \multicolumn{1}{c}{ Sig } \\
\hline Teste log-verossimilhança & & 155,887 & 15 & 0 \\
Teste de Hosmer e Lemeshow & & 5,834 & 8 & 0,666 \\
Cox \& Snell R & & & & \\
Nagelkerke R & 0,214 & & & \\
Pseudo R & 0,285 & & & \\
\hline
\end{tabular}

Fonte: Elaborada pelos autores. 
influenciadoras da existência ou não da certificação nas empresas, não contempladas neste estudo.

A Tabela 4 apresenta uma medida do nível de acerto do modelo. Segundo Hair Junior et al. (2005), para pesquisas exploratórias são aceitáveis níveis de acerto acima de $60 \%$.

Da mesma forma que na regressão múltipla, os coeficientes estimados para as variáveis independentes podem ser avaliados em termos de significância estatística. Nesse sentido, a estatística de Wald (HAIR JUNIOR et al., 2005, p. 235), demonstrada na Tabela 5, é definida como o quadrado da razão entre o coeficiente logístico estimado e o seu erro-padrão. Por meio dessa estatística, que tem distribuição quiquadrado, testa-se a seguinte hipótese estatística para cada variável independente:

\section{$\mathrm{H}_{0}$ : o coeficiente logístico é igual a zero}

Mediante os procedimentos estatísticos realizados, é possível visualizar as variáveis discriminantes,

Tabela 4. Tabela de classificação.

\begin{tabular}{ccrcc}
\hline \multirow{2}{*}{ Observado } & & \multicolumn{3}{c}{ Previsto } \\
\cline { 3 - 4 } & & \multicolumn{1}{c}{ NBR ISO } & 14001 & Porcentagem \\
& & 0 & 1 & regular \\
\cline { 3 - 4 } NBR 1S0 14001 & 0 & 243 & 96 & 71,7 \\
& 1 & 94 & 216 & 69,7 \\
& Porcentagem & & & 70,7 \\
\hline
\end{tabular}

Fonte: Elaborada pelos autores. conforme se observa na Tabela 5. Vale destacar que coeficientes de todas as variáveis incluídas no modelo são estatisticamente diferentes de "0".

Na Tabela 5, pode-se observar que as variáveis “a água é monitorada por indicadores”, “a empresa possui programa estruturado para a gestão da água” e "o consumo de recursos minerais é monitorado por indicadores" são discriminantes para o fato de a empresa ser ou não certificada segundo a norma NBR ISO 14001, pois a significância é inferior a 5\%. Adota-se neste estudo a significância de 5\%, pois, segundo aponta Hair Junior et al. (2005, p. 222), existe pouca justificativa para ir além desse valor.

Observando o valor de $\beta$ expresso na Tabela 5, é possível ainda realizar uma classificação das variáveis em análise. Nesse sentido, observa-se que as três mais importantes são, respectivamente, "a água é monitorada por indicadores", "a empresa possui programa estruturado para a gestão da água" e "o consumo de recursos minerais é monitorado por indicadores".

Mediante a identificação da prevalência das empresas certificadas pela norma NBR ISO 14001 na gestão dos recursos utilizados, condição que atende à expectativa inicial do trabalho, desenvolve-se a necessidade de verificar os recursos que se configuram com maior importância, comparativamente às empresas não certificadas. Novamente, identificando diferenças entre os dois grupos de empresas.

A Tabela 6 expressa a frequência dos programas estruturados para a gestão dos diferentes tipos de

Tabela 5. Variáveis da equação.

\begin{tabular}{|c|c|c|c|c|c|c|}
\hline & $\beta$ & SE & Wald & df & Sig & $\operatorname{Exp}(\mathrm{B})$ \\
\hline A água é monitorada por indicadores. & 1,458 & 0,300 & 23,590 & 1 & 0,000 & 4,298 \\
\hline A água possui processo de reuso. & $-0,038$ & 0,203 & 0,036 & 1 & 0,850 & 0,962 \\
\hline A empresa adota metas de redução no consumo da água. & $-0,162$ & 0,025 & 0,419 & 1 & 0,518 & 0,851 \\
\hline A empresa possui programa estruturado para gestão da água. & 0,770 & 0,258 & 8,932 & 1 & 0,003 & 2,160 \\
\hline $\begin{array}{l}\text { A empresa tem ações de conscientização dos funcionários para o } \\
\text { consumo racional da água. }\end{array}$ & 0,045 & 0,276 & 0,026 & 1 & 0,872 & 1,046 \\
\hline A energia elétrica é monitorada por indicadores. & 0,295 & 0,294 & 1,003 & 1 & 0,317 & 1,343 \\
\hline A empresa adota metas de redução no consumo de energia elétrica. & 0,334 & 0,024 & 1,948 & 1 & 0,163 & 1,397 \\
\hline A empresa possui programa estruturado para gestão da energia elétrica. & 0,303 & 0,255 & 1,411 & 1 & 0,235 & 1,353 \\
\hline $\begin{array}{l}\text { A empresa tem ações de conscientização dos func. para o consumo } \\
\text { racional da energia elétrica. }\end{array}$ & $-0,253$ & 0,265 & 0,910 & 1 & 0,340 & 0,776 \\
\hline O óleo combustível é monitorado por indicadores. & 0,024 & 0,207 & 0,014 & 1 & 0,907 & 1,024 \\
\hline A empresa possui programa estruturado para gestão do óleo combustível. & 0,482 & 0,255 & 3,576 & 1 & 0,059 & 1,619 \\
\hline A empresa possui programa estruturado para gestão de lenha e carvão. & $-0,419$ & 0,382 & 1,203 & 1 & 0,273 & 0,658 \\
\hline 0 consumo de recursos minerais é monitorado por indicadores. & 0,691 & 0,279 & 6,132 & 1 & 0,013 & 1,996 \\
\hline A empresa adota metas de redução no consumo de recursos minerais. & $-0,043$ & 0,314 & 0,019 & 1 & 0,891 & 0,958 \\
\hline A empresa possui programa estruturado para gestão dos recursos minerais. & $-0,301$ & 0,412 & 0,535 & 1 & 0,464 & 0,740 \\
\hline
\end{tabular}


Tabela 6. Prioridade de gestão dos recursos nas empresas.

\begin{tabular}{|c|c|c|c|c|c|c|c|}
\hline & & \multicolumn{3}{|c|}{ Empresas certificadas NBR ISO 14001} & \multicolumn{3}{|c|}{ Empresas não certificadas } \\
\hline & & $\begin{array}{c}\text { Empresas } \\
\text { que possuem } \\
\text { programa } \\
\text { estruturado de } \\
\text { gestão }\end{array}$ & $\begin{array}{l}\text { Porcentagem } \\
\text { em relação às } \\
310 \text { empresas } \\
\text { certificadas } \\
\text { 1SO } 14001(\%)\end{array}$ & $\begin{array}{l}\text { Porcentagem } \\
\text { em relação às } \\
649 \text { empresas } \\
\text { estudadas } \\
(\%)\end{array}$ & $\begin{array}{c}\text { Empresas } \\
\text { que possuem } \\
\text { programa } \\
\text { estruturado de } \\
\text { gestão }\end{array}$ & $\begin{array}{c}\text { Porcentagem } \\
\text { em relação às } \\
339 \text { empresas } \\
\text { não certificadas } \\
\text { 1SO } 14001(\%)\end{array}$ & $\begin{array}{c}\text { Porcentagem } \\
\text { em relação às } \\
649 \text { empresas } \\
\text { estudadas } \\
(\%)\end{array}$ \\
\hline 1 & Energia elétrica & 160 & 51,6 & 24,7 & 83 & 24,5 & 12,8 \\
\hline 2 & Água & 148 & 47,7 & 22,8 & 61 & 18,0 & 9,4 \\
\hline 3 & Óleo combustível & 99 & 31,9 & 15,3 & 48 & 14,2 & 7,4 \\
\hline 4 & Recurso mineral & 38 & 12,3 & 5,9 & 20 & 5,9 & 3,1 \\
\hline 5 & Lenha/carvão & 26 & 8,4 & 4,0 & 17 & 5,0 & 2,6 \\
\hline
\end{tabular}

recursos para as 310 empresas certificadas pela norma NBR ISO 14001 e para as 339 não certificadas.

A condição de proximidade entre o volume de empresas certificadas pela norma NBR ISO 14001 com $47,8 \%$ e as não certificadas com 52,2\% fica evidenciada na Tabela 6 , com destaque que ambos os grupos apresentaram a mesma sequência de prioridades na existência de programas estruturados de gestão dos recursos, ou seja, a energia elétrica, a água, o óleo combustível, o recurso mineral e a lenha/o carvão. Os dados demonstram ainda que o volume de empresas certificadas pela norma NBR ISO 14001 é praticamente o dobro em todos os itens de análise na comparação com as empresas não certificadas.

\section{Considerações finais}

0 presente artigo se propôs a verificar se as empresas certificadas pela norma NBR ISO 14001 apresentam procedimentos de gestão ambiental diferentes dos adotados pelas empresas não certificadas por essa norma. A pesquisa comparou empresas certificadas pela norma NBR ISO 14001 com as não certificadas, concluindo pela presença de procedimentos de gestão distintos no que se refere aos recursos: água, energia elétrica, óleo combustivel, lenha/carvão e recursos minerais.

A água é um recurso que aparece com predominância na gestão das empresas certificadas NBR ISO $14001 \mathrm{em}$ todos os itens analisados. 0 fato de a empresa ser certificada pela norma NBR ISO 14001 constitui um diferencial no processo de gestão da água.

A energia elétrica também é um recurso que aparece com predominância na gestão das empresas certificadas NBR ISO 14001. A única variável que não se constitui com predominância é o processo de conscientização dos funcionários para o consumo racional desse recurso. Pode-se inferir que o fato de a empresa ser certificada pela norma NBR ISO 14001 constitui um diferencial no processo de gestão da energia elétrica.

0 óleo combustivel é um recurso que aparece com predominância na gestão das empresas certificadas NBR ISO 14001, no monitoramento e na existência de programas estruturados, mas não na existência de metas de redução. Como em dois dos três itens analisados observou-se predominância, pode-se inferir que o fato de a empresa ser certificada pela norma NBR ISO 14001 constitui um diferencial no processo de gestão do óleo combustível.

A constatação da presença de controles no consumo de água, energia elétrica e óleo combustível corrobora a visão de Boiral (2007) com relação à importância do grau de integração das práticas preconizadas pela NBR ISO 14001 e as atividades operacionais. Fica evidente que, de modo geral, as empresas certificadas tendem a apresentar um elevado grau de integração da NBR ISO 14001 à estrutura organizacional.

Apesar de a NBR ISO 14001 não explicitar critérios de avaliação de desempenho ambiental, conforme apontado por Delmas (2003), observa-se que as empresas certificadas possuem, em sua maioria, indicadores de controle de recursos. Esse cenário vai ao encontro da abordagem de González, Sarkis e Adenso-Diaz (2008), comprovando que as empresas certificadas na NBR ISO 14001 incorporaram práticas de gestão dos recursos com implicações importantes para a preservação ambiental.

0 fato de as empresas certificadas NBR ISO 14001 não serem predominantes no âmbito das metas de redução de óleo combustível abre espaço para futura análise. Se há existência de indicadores e de programas estruturados, seria uma ocorrência normal que esse grupo de empresas objetivasse reduzir esse consumo por meio de avanços tecnológicos ou ações em seus processos. 
A lenha e o carvão são recursos que não aparecem com predominância na gestão das empresas certificadas NBR ISO 14001. A não predominância de empresas certificadas NBR ISO 14001 demonstra que esses itens não se destacam no processo de gestão dos recursos. Ressalte-se que apenas 20\% das empresas pesquisadas utilizam esse recurso e $6,6 \%$ possuem programas estruturados voltados para essa gestão.

Os recursos minerais aparecem com predominância na gestão das empresas certificadas NBR ISO 14001 em todas as variáveis de análise. Registre-se que $40 \%$ das empresas pesquisadas utilizam esse recurso e $8,9 \%$ possuem programas estruturados voltados para essa gestão.

Os dados apontam que as empresas certificadas NBR ISO 14001 demonstram uma maior preocupação com a gestão ambiental, a qual se expressa por meio de controles, ações e programas estruturados para os recursos empregados. A gestão das empresas certificadas NBR ISO 14001 se diferencia assim do mercado, proporcionando benefícios ambientais para toda a sociedade.

Os principais fatores discriminantes na gestão das empresas certificadas NBR ISO 14001 são o monitoramento e a presença de programas estruturados para a água e o monitoramento dos recursos minerais.

Por certo não é possível assegurar que fator influencia de forma preponderante a incorporação das variáveis ambientais pelas empresas, mas é possível afirmar que a certificação pela norma NBR ISO 14001 interfere de forma positiva na administração das organizações. No entanto, nada se pode afirmar com relação aos impactos da certificação sobre a performance ambiental, conforme as pesquisas empreendidas por Anton, Deltas e Khanna (2004), Potoski e Prakash (2005) e Arimura, Hibikid e Katayama (2008).

Abre-se, nessa direção, um campo para futuras pesquisas. Trata-se de aprofundar a discussão dos impactos da certificação NBR ISO 14001 sobre a adoção de inovações tecnológicas associadas à preservação do meio ambiente, assim como identificar os benefícios derivados da prática. Como referência, além dos trabalhados citados, a pesquisa de Yin e Schmeidler (2009).

\section{Referências}

ANÁlISE GESTÃO AMBIENTAL. São Paulo: Análise Editorial, 2008.

ANTON, W.; DELTAS, G.; KHANNA, M. Environmental management systems: do they improve environmental performance?. Journal of Environmental Economics and Management, v. 48, n. 1, p. 632-654, 2004. http:// dx.doi.org/10.1016/j.jeem.2003.06.003
ARIMURA, T.; HIBIKID, H. A.; KATAYAMA, H. Is a voluntary approach an effective environmental policy instrument? A case for environmental management systems. Journal of Environmental Economics and Management, v. 55, n. 3, p. 281-295, 2008. http://dx.doi.org/10.1016/j. jeem.2007.09.002

ASSOCIAÇÃO BRASILEIRA DE NORMAS TÉCNICAS - ABNT. NBR ISO 14001: Sistemas de Gestão Ambiental Requisitos com orientação para o uso. Rio de Janeiro: ABNT, 2004.

BARBIERI, J. C. Gestão ambiental empresarial. São Paulo: Saraiva, 2007.

BOIRAL, O. ISO 9000, outside the iron cage. Organization Science, v. 14, n. 6, p. 720-737, 2003. http://dx.doi. org/10.1287/orsc. 14.6.720.24873

BOIRAL, O. Corporate greening through ISO 14001: a rational myth?. Organization Science, v. 18, n. 1, p. 127-146, 2007. http://dx.doi.org/10.1287/orsc.1060.0224

CERVO, A. L.; BERVIAN, P. A.; SILVA, R. Metodologia científica. 6. ed. São Paulo: Pearson Prentice Hall, 2007.

DELMAS, M. In search of 1SO: an institutional perspective on the adoption of international management standards. 2003. Stanford Graduate School of Business Research Paper, n. 1784.

FRANCO, T. Padrões de produção e consumo nas sociedades urbano-industriais e suas relações com a degradação da saúde e do meio ambiente. In: MINAYO, M. C. S. (Org.). Saúde e ambiente sustentável: estreitando nós. Rio de Janeiro: Fiocruz, 2002.

FRYXELL, G. E.; SZETO, A. The influence of motivations for seeking ISO 14001 Certification: an empirical study of ISO 14001 certified facilities in Hong Kong. Journal of Environmental Management, v. 65, n. 3, p. 223-238, 2002. PMid:12357656. http://dx.doi. org/10.1006/jema.2001.0538

GONZÁLEZ, P; SARKIS, J.; ADENSO-DIAZ, B. Environmental management system certification and its influence on corporate practices: Evidence from the automotive industry. International Journal of Operations \& Production Management, v. 28, n. 11, p. 1.021-1.041, 2008.

HAIR JUNIOR, J. F. et al. Análise multivariada de dados. 5. ed. Porto Alegre: Bookman, 2005.

HOFFMAN, A. J. Climate change strategy: the business logic behind voluntary greenhouse gas reduction. California Management Review, v. 47, n. 3, p. 21-46, 2005.

JIANG, R. J.; BANSAL, P. Seeing the need for ISO 14001. Journal of Management Studies, v. 40, n. 4, p. 1.047-1.067, 2003.

KHANNA, M.; DELTAS, G.; HARRINGTON, D. R. Adoption of pollution prevention techniques: the role of management systems and regulatory pressures. Environmental and Resource Economics, v. 44, n. 1, p. 85-106, 2009. http:// dx.doi.org/10.1007/s10640-009-9263-y

OLIVEIRA, O. J.; SERRA, J. R. Benefícios e dificuldades da gestão ambiental com base na ISO $14001 \mathrm{em}$ empresas industriais de São Paulo. Produção, v. 20, n. 3, p. 429-438, 2010. http://dx.doi.org/10.1590/S010365132010005000013

POTOSKI, M.; PRAKASH, A. Covenants with weak swords: ISO 14001 and facilities' environmental performance. Journal of Policy Analysis and Management, v. 24, n. 4, p. 745-769, 2005. http://dx.doi.org/10.1002/pam.20136 
PREARO, L. C. O uso de técnicas estatísticas multivariadas em dissertações e teses sobre o comportamento do consumidor. um estudo exploratório. Dissertação de mestrado. Universidade de São Paulo. São Paulo, 2008.

ROHRICH, S. S.; CUNHA, J. C. A proposição de uma taxonomia para a análise da gestão ambiental no Brasil. Revista de Administração Contemporânea, v. 8, n. 4, p. 86-95, 2004.

SEIFFERT, M. E. B. ISO 14001: Sistemas de Gestão Ambiental. São Paulo: Atlas, 2005.

SLACK, N. et al. Administração da produção. São Paulo: Atlas, 2002.

YIN, H. ISO 14001 certification: engine or signal for good environmental performance?. Wharthon University of Pensylvania, 2003. Working Paper. Disponivel em: $<$ http://opim.wharton.upenn.edu/risk/library/WP200307_1SO-Cert.pdf>.

YIN, H.; SCHMEIDLER, P. J. Why do standardized ISO 14001 environmental management systems lead to heterogeneous environmental outcomes?. Business Strategy and the Environment Business Stratategy Environment, v. 18, n. 4, p. 469-486, 2009. http:// dx.doi.org/10.1002/bse.629

ZENG, S. X. et al. Towards implementation of ISO 14001 environmental management systems in selected industries in China. Journal of Cleaner Production, v. 13, n. 7, p. 645-656, 2005. http://dx.doi.org/10.1016/j. jclepro.2003.12.009

\title{
Managementof natural resources in organizations certified by NBR ISO 14001 standard
}

\begin{abstract}
This study focuses on a set of variables associated with control processes and actions to mitigate the consumption of resources in operations in order to determine whether the companies certified by NBR ISO 14001 standard have environmental management procedures significantly different from those adopted by the companies which are not certified. It is a descriptive research based on a sample of 649 companies of different businesses which provided information for publication in the journal "Análise Gestão Ambiental" (2008). The objects of this study were the following: water, electricity, fuel, wood/coal and mineral resources. Using statistical analysis, embodied in the logistic regression and chi-square test, it was observed that the companies certified by NBR ISO 14001 standard invest in a larger set of environmental factors in their management, through controls, actions, and programs structured to reduce the impact of their operations on the environment.
\end{abstract}

\section{Keywords}

Environmental management. Environmental management system. ISO 14001. 